\title{
Health Inequalities in Rio de Janeiro, Brazil: Lower Healthy Life Expectancy in Socioeconomically Disadvantaged Areas
}

\author{
| Célia Landmann Szwarcwald, PhD, Jurema Corrêa da Mota, MS, Giseli Nogueira Damacena, MS, and Tatiana Guimarães Sardinha Pereira, BA
}

Recent studies on health inequality have focused on individual characteristics such as education, income, or ethnicity, as well as group characteristics, to explain social and spatial variations in health. ${ }^{1-7}$ Highlighting inequalities at the local level is especially important, because social and environmental conditions have been shown to be significant determinants of health status. ${ }^{8}$

The majority of geographical health studies have analyzed mortality data, largely because they are readily accessible. However, increased longevity in developed countries has resulted in a greater emphasis on the quality of the later years. ${ }^{9,10}$ A long life does not necessarily mean a healthy life, as an increase in years lived is often accompanied by an increase in chronic morbidity and disability. ${ }^{11}$ As such, it is generally agreed upon that mortality indicators alone are insufficient to appropriately characterize the state of a population's health. ${ }^{12}$ Newer, more relevant indicators such as quality-adjusted life years and disability-adjusted life years, which combine mortality data with morbidity and disability data, provide methods to investigate and compare the burden of diseases. ${ }^{13}$

Over the past 4 decades, different health indicators that consider morbidity, functional limitations, and disabilities along with mortality have been proposed. ${ }^{14-16}$ A single measure of morbidity and mortality obtained by the Sullivan method (healthy life expectancy) ${ }^{17}$ has been the most frequently used. ${ }^{14}$ It estimates the number of years a person of a given population may expect to enjoy full health. Variations of this measure are established by different definitions of healthy, which are usually based on selfperceived health, long-term illness or disability, and functional or cognitive limitations.

The summarized measures of morbidity and mortality obtained by the Sullivan method have been adopted for monitoring health inequalities in many developed countries. ${ }^{18}$ In the United Kingdom, the regional variation in healthy life expectancy (as measured by limiting

Objectives. We investigated deprivation and inequalities in life expectancy and healthy life expectancy by location in Rio de Janeiro, Brazil.

Methods. We conducted a health survey of 576 adults in 2006. Census tracts were stratified by income level and categorization as a slum. We determined health status by degree of functional limitation, according to the approach proposed by the World Health Organization. We calculated healthy life expectancies by Sullivan's method with abridged life table.

Results. We found the worst indicators in the slum stratum. The life expectancy at birth of men living in the richest parts of the city was 12.8 years longer than that of men living in deprived areas. For both men and women older than age 65 years, healthy life expectancy was more than twice as high in the richest sector as in the slum sector.

Conclusions. Our analysis detailed the excess burden of poor health experienced by disadvantaged populations of Rio de Janeiro. Policy efforts are needed to reduce social inequalities in health in this city, especially among the elderly. (Am J Public Health. 2011;101:517-523. doi:10.2105/AJPH.2010. 195453)

long-standing illness) has been found to be much greater than are the regional variations in life expectancy. ${ }^{19}$ Studies in other countries have produced similar findings. ${ }^{20,21}$ Substantial inequalities in healthy life years among persons aged 50 years were also found in European Union countries, with greater variation in healthy life expectancy than in life expectancy. ${ }^{22}$

In Brazil, differences in mortality across regions have been well documented, often with a steep north-south gradient. ${ }^{23,24}$ These inequalities persist; the more prosperous southern states have lower infant mortality and higher life expectancies. Small-area variations in health indicators in large Brazilian cities are also evident, reflecting socioeconomic and environmental inequalities. $^{25-28}$

In Rio de Janeiro, Brazil, mortality studies have established an association between adverse health outcomes and residential concentration of poverty. The worst health indicators were found in the sector of the city with the highest concentration of slum residents, which also had an extremely high homicide rate. ${ }^{29} \mathrm{~A}$ geographic study in Goiânia, a newly urbanized city of Brazil, also detected a spatial cluster of violent deaths on its outskirts. ${ }^{30}$ This cluster had a significantly higher proportion of people with the lowest educational level and income and the worst housing conditions in the city.

Whether these conditions are associated with differences in quality of life for older adults has been less well studied. In Brazil, healthy life expectancy was estimated for the total adult population ${ }^{31,32}$ and for the elderly in the city of São Paulo, ${ }^{33}$ but this measure has not been used to monitor inequalities in quality of life among older persons.

We examined deprivation and inequalities in total life expectancy and healthy life expectancy by location in the municipality of Rio de Janeiro. We calculated healthy life expectancy with the approach developed by the World Health Organization (WHO), ${ }^{34}$ in which healthy status is established by degree of functional limitation, with data from a survey carried out in the city during 2006.

\section{METHODS}

As part of a project developed by the WHO to assess health system performance of member countries, the World Health Survey was administered in Brazil in 2003. ${ }^{35}$ In 2006, 
we adapted the survey questionnaire to assess the performance of the Brazilian Health System, with a focus on primary care. We conducted the survey in several large Brazilian cities, ${ }^{36}$ including Rio de Janeiro.

In Rio de Janeiro, the study design encompassed 4 strata, each an aggregation of census tracts with different socioeconomic characteristics. The Brazilian Institute of Geography and Statistics defines a slum tract as a community with 50 or more households illegally occupying land that is haphazardly arranged and lacks essential public services. We used this definition along with mean monthly incomes of household heads to determine the following sectors of the city:

1. Slum sector, composed of all slum census tracts;

2. Poor sector, composed of all nonslum census tracts with mean monthly income less than or equal to US $\$ 350$;

3. Intermediate sector, composed of all census tracts with mean monthly income greater than US\$350 and less than or equal to US \$1000; and

4. Rich sector, composed of all census tracts with mean monthly income greater than US $\$ 1000$.
We conducted the health survey in 576 Rio de Janeiro households (144 households per stratum). The sample design was derived from traditional household surveys, with 3 selection stages: census tracts, households, and adult residents (aged 18 years or older). First, we allocated census tracts to 1 of the 4 strata. For each stratum, we selected 9 tracts, with probability proportional to the number of households in the census tract. In each census tract, we randomly selected 16 households. In the last stage, we randomly selected 1 adult per household to participate in the survey. We used a weighting calibration procedure to adjust for the census population distribution by income, gender, and age group. Because the study design involved stratification of census tracts and multiple-stage cluster selection, we considered the complex sample design in the statistical analysis. ${ }^{37}$

The questionnaire asked about household and sociodemographic characteristics, self-perception of health, and degree of difficulty in carrying out activities of daily living. In the analysis, we examined differences in household characteristics by strata. We considered 4 indicators: educational level of the household head (incomplete elementary school, incomplete fundamental school, incomplete secondary school, or complete secondary education or more), number of residents per room in the household, number of bathrooms per household, and household assets, defined by the sum of such items as refrigerator, television, stereo, washing machine, land-line telephone, cellular telephone, computer, microwave, dishwasher, and automobile.

\section{Health Domains}

We based our definition of health on the approach proposed by the WHO in the International Classification of Functionality, Disability, and Health, ${ }^{38}$ in which limitations to activities and functionality are viewed not only as a consequence of illness but also as important components of an individual's health.

We examined 2 components of disability: activity limitations and deficiencies in function and body structure. Respondents were asked about functional disabilities in 6 domains: (1) daily activities ("Overall, in the last 30 days, how much difficulty did you have performing work or household activities?"), (2) mobility ("Overall, in the last 30 days, how much difficulty did you have with moving around?"), (3) self-care ("Overall, in the last 30 days, how much difficulty did you have with self-care, such as washing or dressing yourself?"), (4)

TABLE 1-Characteristics by Socioeconomic Stratum: Rio de Janeiro, Brazil, 2006

\begin{tabular}{|c|c|c|c|c|}
\hline & Slum Sector, \% (95\% Cl) & Poor Sector, \% (95\% Cl) & Intermediate Sector, \% (95\% Cl) & Rich Sector, \% (95\% Cl) \\
\hline \multicolumn{5}{|l|}{ Educational level of household head } \\
\hline Incomplete elementary school & $33.8(26.0,42.2)$ & $19.5(13.6,27.1)$ & $8.8(5.0,15.1)$ & $0.6(0.1,4.1)$ \\
\hline Incomplete fundamental school & $38.3(30.1,47.3)$ & $27.4(20.3,35.9)$ & $15.1(10.0,22.0)$ & $4.9(2.0,11.8)$ \\
\hline Incomplete secondary school & $17.7(11.8,25.8)$ & $22.9(16.2,31.3)$ & $13.7(8.8,20.7)$ & $2.5(0.9,6.9)$ \\
\hline$\geq$ Complete secondary school & $10.2(5.9,17.2)$ & $30.2(22.7,38.9)$ & $62.5(53.9,70.3)$ & $92.0(85.1,95.8)$ \\
\hline \multicolumn{5}{|l|}{ Household assets, ${ }^{a}$ no. } \\
\hline $0-3$ & $23.5(16.9,31.8)$ & $11.4(7.0,17.8)$ & $4.9(2.4,9.7)$ & $0.6(0.1,4.2)$ \\
\hline $4-7$ & $73.8(65.5,80.7)$ & $75.4(67.3,82.1)$ & $62.7(54.1,70.5)$ & $25.7(18.2,35.0)$ \\
\hline$\geq 8$ & $2.6(1.0,7.1)$ & $13.2(8.4,20.2)$ & $32.4(25.0,40.9)$ & $73.7(64.5,81.2)$ \\
\hline Residents per room in household, no. & $1.9(1.7,2.2)$ & $1.4(1.3,1.6)$ & $1.1(1.0,1.2)$ & $0.8(0.7,0.8)$ \\
\hline \multicolumn{5}{|l|}{ Bathrooms in household, no. } \\
\hline$\leq 1$ & $92.2(86.2,95.7)$ & $83.8(76.4,89.2)$ & $66.4(57.9,74.0)$ & $18.1(12.0,26.4)$ \\
\hline 2 & $6.4(3.3,12.1)$ & $15.0(9.9,22.2)$ & $28.9(21.8,37.2)$ & $36.9(28.6,46.0)$ \\
\hline$\geq 3$ & $1.4(0.4,5.6)$ & $1.2(0.2,6.6)$ & $4.7(2.1,10.2)$ & $45.0(36.4,53.9)$ \\
\hline
\end{tabular}

Note. $\mathrm{Cl}=$ confidence interval. The slum sector was composed of all slum census tracts, the poor sector was composed of all nonslum census tracts with mean monthly income less than or equal to US $\$ 350$, the intermediate sector was composed of all census tracts with mean monthly income greater than US $\$ 350$ and less than or equal to US $\$ 1000$, and the rich sector was composed of all census tracts with mean monthly income greater than US $\$ 1000$.

${ }^{a}$ Sum of such items as refrigerator, television, stereo, washing machine, land-line telephone, cellular telephone, computer, microwave, dishwasher, and automobile. 
TABLE 2-Life Expectancy by Age, Gender, and Socioeconomic Stratum: Rio de Janeiro, Brazil, 2006

\begin{tabular}{|c|c|c|c|c|}
\hline \multirow[b]{2}{*}{ Age, y } & \multicolumn{4}{|c|}{ Life Expectancy, y } \\
\hline & Slum Sector & Poor Sector & Intermediate Sector & Rich Sector \\
\hline \multicolumn{5}{|l|}{ Females } \\
\hline 0 & 71.6 & 75.6 & 78.0 & 81.4 \\
\hline 1 & 71.8 & 75.5 & 77.9 & 81.1 \\
\hline 5 & 68.1 & 71.7 & 74.1 & 77.2 \\
\hline 10 & 63.2 & 66.8 & 69.2 & 72.2 \\
\hline 15 & 58.4 & 61.9 & 64.2 & 67.2 \\
\hline 20 & 53.7 & 57.0 & 59.4 & 62.4 \\
\hline 25 & 48.9 & 52.2 & 54.6 & 57.5 \\
\hline 30 & 44.5 & 48.4 & 50.3 & 52.6 \\
\hline 35 & 39.9 & 43.7 & 45.6 & 47.8 \\
\hline 40 & 35.4 & 39.1 & 41.0 & 43.1 \\
\hline 45 & 31.1 & 34.6 & 36.4 & 38.4 \\
\hline 50 & 27.1 & 30.3 & 32.0 & 33.9 \\
\hline 55 & 23.2 & 26.1 & 27.9 & 29.4 \\
\hline 60 & 19.7 & 22.3 & 23.9 & 25.1 \\
\hline 65 & 16.0 & 18.7 & 20.1 & 21.0 \\
\hline 70 & 12.7 & 15.3 & 16.6 & 17.0 \\
\hline$\geq 75$ & 9.8 & 12.6 & 13.4 & 13.1 \\
\hline \multicolumn{5}{|l|}{ Males } \\
\hline 0 & 60.9 & 64.0 & 67.1 & 73.7 \\
\hline 1 & 61.0 & 64.0 & 67.0 & 73.4 \\
\hline 5 & 57.3 & 60.1 & 63.1 & 69.6 \\
\hline 10 & 52.5 & 55.3 & 58.3 & 64.7 \\
\hline 15 & 47.7 & 50.4 & 53.4 & 59.7 \\
\hline 20 & 43.8 & 46.2 & 49.3 & 55.2 \\
\hline 25 & 40.0 & 42.3 & 45.1 & 50.7 \\
\hline 30 & 35.9 & 38.3 & 40.9 & 46.1 \\
\hline 35 & 31.6 & 34.1 & 36.6 & 41.5 \\
\hline 40 & 27.5 & 29.7 & 32.1 & 36.9 \\
\hline 45 & 23.4 & 25.4 & 28.0 & 32.6 \\
\hline 50 & 19.9 & 21.6 & 24.0 & 28.1 \\
\hline 55 & 16.7 & 18.2 & 20.3 & 24.0 \\
\hline 60 & 14.0 & 15.1 & 17.0 & 20.1 \\
\hline 65 & 11.2 & 12.1 & 13.8 & 16.5 \\
\hline 70 & 8.6 & 9.3 & 10.9 & 12.9 \\
\hline$\geq 75$ & 6.3 & 7.1 & 8.2 & 9.8 \\
\hline
\end{tabular}

Note. The slum sector was composed of all slum census tracts, the poor sector was composed of all nonslum census tracts with mean monthly income less than or equal to US $\$ 350$, the intermediate sector was composed of all census tracts with mean monthly income greater than US $\$ 350$ and less than or equal to US $\$ 1000$, and the rich sector was composed of all census tracts with mean monthly income greater than US $\$ 1000$.

sensation of pain ("Overall, in the last 30 days, how much bodily aches or pains did you have?"), (5) learning (“In the last 30 days, how much difficulty did you have in learning a new task [for example, learning how to get to a new place, learning a new game, learning a new recipe, etc.]?"), and (6) vision ("In the last 30 days, how much difficulty did you have in seeing and recognizing a person you know across the street [i.e., from a distance of about $20 \mathrm{~m}$ ]? and "In the last 30 days, how much difficulty did you have in seeing and recognizing an object at arm's length or in reading?").

We scored each item from 1 to 5 according to level of difficulty in undertaking the activity (1=none, $2=$ mild, $3=$ moderate, $4=$ severe, $5=$ extreme). No or mild difficulty was recoded as zero, moderate difficulty as 1 , and severe or extreme as 2. For vision, we considered severe or extreme answers in either of the 2 questions to be a severe vision difficulty. We calculated the total disability score from the sum of the 6 items (minimum of 0 and maximum of 12 ; with the 2 vision responses combined). We used the threshold of 3 in the total disability score to define healthy status $($ score $<3$ ) and poor health status (score $\geq 3$ ).

\section{Statistical Methods}

We calculated healthy life expectancies by Sullivan's method ${ }^{17}$ with an abridged life table. We obtained mortality data for 2006 from the Health Department of Rio de Janeiro. We used a geographic information system to geocode the addresses and to classify census tracts into the 4 strata. The census provided population data from 2000, which we used to estimate the 2006 strata populations by gender and age group. We also obtained mortality rates by gender, age (in 5-year age groups) and stratum.

To explore inequalities, we compared mean disability scores among strata and fitted a multivariate logistic regression model with poor health status as the response variable, adjusted for gender, age, and educational level. Because sample sizes in the gender and age categories were small, we used a logistic regression model with age and gender as covariates to estimate the probabilities of healthy status. We then used the predicted probabilities by 5-year age groups and gender to estimate healthy life expectancies in each stratum.

\section{RESULTS}

The proportional distribution of households by strata according to socioeconomic characteristics is shown in Table 1. We found marked inequalities. Although 2 sectors were impoverished, only 1 was classified as a slum, and in all indicators the poor sector fared better than the slum sector. Among slum household 
TABLE 3-Mean Disability Score by Age Group, Gender, and Socioeconomic Strata: Rio de Janeiro, Brazil, 2006

\begin{tabular}{lcccc}
\hline Age Group, $y$ & $\begin{array}{c}\text { Slum Sector, } \\
\text { Mean Score (SE) }\end{array}$ & $\begin{array}{c}\text { Poor Sector, } \\
\text { Mean Score (SE) }\end{array}$ & $\begin{array}{c}\text { Intermediate Sector, } \\
\text { Mean Score (SE) }\end{array}$ & $\begin{array}{c}\text { Rich Sector, } \\
\text { Mean Score (SE) }\end{array}$ \\
\hline $\begin{array}{l}\text { Women } \\
18-59\end{array}$ & $1.3148(0.2953)$ & $1.1667(0.2331)$ & $1.0556(0.2055)$ & $0.3704(0.1161)$ \\
$\geq 60$ & $3.3889(0.9152)$ & $3.5556(0.7104)$ & $2.1667(0.6679)$ & $0.5000(0.2322)$ \\
$\begin{array}{l}\text { Men } \\
18-59\end{array}$ & $0.8704(0.2048)$ & $0.3704(0.1099)$ & $0.3519(0.1095)$ & $0.3333(0.0877)$ \\
$\geq 60$ & $2.0556(0.5330)$ & $1.8333(0.5955)$ & $1.2222(0.4683)$ & $0.5556(0.2455)$ \\
Total & & & & \\
$18-59$ & $1.0926(0.1802)$ & $0.7685(0.1339)$ & $0.7037(0.1208)$ & $0.3519(0.0724)$ \\
$\geq 60$ & $2.7222(0.5339)$ & $2.6944(0.4794)$ & $1.6944(0.4098)$ & $0.5278(0.1666)$
\end{tabular}

Note. The slum sector was composed of all slum census tracts, the poor sector was composed of all nonslum census tracts with mean monthly income less than or equal to US $\$ 350$, the intermediate sector was composed of all census tracts with mean monthly income greater than US $\$ 350$ and less than or equal to US $\$ 1000$, and the rich sector was composed of all census tracts with mean monthly income greater than US $\$ 1000$. heads, 33.8\% did not complete elementary school; only $19.5 \%$ of their counterparts in the poor sector had only this level of education. By contrast, in the wealthiest area, only $0.6 \%$ of household heads did not complete elementary school, and 92\% completed secondary school.
We observed similar patterns in household assets, with the highest accumulation in the wealthiest sector. Differences in crowding were also pronounced; the mean number of residents per household room was 0.8 among the wealthy and 1.9 in slum households. In
TABLE 4-Logistic Regression Model Results With Poor Health Status as the Response Variable: Rio de Janeiro, Brazil, 2006

\begin{tabular}{|c|c|c|}
\hline & $O \mathrm{R}^{\mathrm{a}}(95 \% \mathrm{Cl})$ & $P$ \\
\hline \multicolumn{3}{|l|}{ Gender } \\
\hline Women (Ref) & 1.00 & \\
\hline Men & $0.38(0.22,0.64)$ & $<.001$ \\
\hline \multicolumn{3}{|l|}{ Age, y } \\
\hline $18-29$ & $0.08(0.03,0.25)$ & $<.001$ \\
\hline $30-39$ & $0.33(0.16,0.67)$ & .002 \\
\hline $40-59$ & $0.52(0.28,0.96)$ & .036 \\
\hline$\geq 60$ (Ref) & 1.00 & \\
\hline \multicolumn{3}{|l|}{ Educational level } \\
\hline Incomplete elementary school & $1.89(0.99,3.61)$ & .056 \\
\hline Complete elementary school (Ref) & 1.00 & \\
\hline \multicolumn{3}{|l|}{ Socioeconomic stratum } \\
\hline Slum & $3.02(1.12,8.16)$ & .029 \\
\hline Poor & $2.83(1.10,7.27)$ & .03 \\
\hline Intermediate & $2.78(1.13,6.80)$ & .026 \\
\hline Rich (Ref) & 1.00 & $\ldots$ \\
\hline
\end{tabular}

Note. $\mathrm{OR}=$ odds ratio; $\mathrm{Cl}=$ confidence interval. The slum sector was composed of all slum census tracts, the poor sector was composed of all nonslum census tracts with mean monthly income less than or equal to US $\$ 350$, the intermediate sector was composed of all census tracts with mean monthly income greater than US $\$ 350$ and less than or equal to US $\$ 1000$, and the rich sector was composed of all census tracts with mean monthly income greater than US $\$ 1000$.

${ }^{a}$ Derived from a logistic regression model adjusted for age, gender, educational level, and stratum. addition, $45 \%$ of households located in the richest stratum had 3 or more bathrooms; less than $1.5 \%$ of poor and slum households had as many.

The life tables showed distinct mortality patterns by strata (Table 2). The life expectancy variation was proportional to socioeconomic level: the wealthier the sector, the greater the longevity. The slum sector had the shortest life expectancy for both men and women at all ages. The life expectancy at birth of men living in the wealthiest parts of the city was 12.8 years longer than that of men living in deprived areas. The differences by strata among women were also pronounced, although smaller.

The mean disability score by gender, age, and stratum is shown in Table 3. The wealthiest residents had the best scores for both genders and age groups. The gaps between rich and poor were large: the mean disability score varied from 1.09 to 0.35 among individuals younger than 60 years, and from 2.72 to 0.53 among older persons, indicating that the poor elderly averaged more than 2 severe conditions and that almost half their counterparts in rich neighborhoods did not have any. Women had higher disability scores than did men in both age groups in all strata, except for the wealthiest stratum and older age group. The steepest socioeconomic gradient appeared among women aged 60 years or older, the slightest among men younger than 60 years.

When we modeled the variation across strata for poor health status (disability score $\geq 3$ ) adjusted for educational level, gender, and age, we found statistically significant effects for all 3 strata in comparison with the wealthiest one (Table 4). The proportion of individuals with disabilities increased with age and among females, but educational level did not have a statistically significant effect. The slum sector showed the highest effect, followed by the poor and intermediate sectors.

The estimated healthy life expectancies by gender, age group (for individuals aged $\geq 20$ years), and strata are shown in Table 5. Because women lived more years in poor health or with limitations, the differences in healthy life expectancy between men and women were smaller than were the differences in life expectancy for all age groups. However, the percentage of lost years of healthy life was much higher among women. Among the 
TABLE 5-Life Expectancy and Healthy Life Expectancy by Gender, Age, and Socioeconomic Stratum: Rio de Janeiro, Brazil, 2006

\begin{tabular}{|c|c|c|c|c|c|c|c|c|c|c|c|c|}
\hline \multirow[b]{2}{*}{ Age, y } & \multicolumn{3}{|c|}{ Slum Sector } & \multicolumn{3}{|c|}{ Poor Sector } & \multicolumn{3}{|c|}{ Intermediate Sector } & \multicolumn{3}{|c|}{ Rich Sector } \\
\hline & $\begin{array}{c}\text { Life } \\
\text { Expectancy, y }\end{array}$ & $\begin{array}{l}\text { Healthy Life } \\
\text { Expectancy, y }\end{array}$ & $\begin{array}{l}\text { Healthy Life } \\
\text { Lost, y (\%) }\end{array}$ & $\begin{array}{c}\text { Life } \\
\text { Expectancy, y }\end{array}$ & $\begin{array}{l}\text { Healthy Life } \\
\text { Expectancy, y }\end{array}$ & $\begin{array}{l}\text { Healthy Life } \\
\text { Lost, y (\%) }\end{array}$ & $\begin{array}{l}\text { Life } \\
\text { Expectancy, y }\end{array}$ & $\begin{array}{l}\text { Healthy Life } \\
\text { Expectancy, y }\end{array}$ & $\begin{array}{l}\text { Healthy Life } \\
\text { Lost, y (\%) }\end{array}$ & $\begin{array}{c}\text { Life } \\
\text { Expectancy, y }\end{array}$ & $\begin{array}{l}\text { Healthy Life } \\
\text { Expectancy, y }\end{array}$ & $\begin{array}{l}\text { Healthy Life } \\
\text { Lost, y (\%) }\end{array}$ \\
\hline \multicolumn{13}{|l|}{ Women } \\
\hline 20 & 53.7 & 37.1 & $16.6(30.9)$ & 57.0 & 40.8 & $16.2(28.4)$ & 59.4 & 44.9 & $14.5(24.4)$ & 62.4 & 56.2 & $6.2(9.9)$ \\
\hline 25 & 48.9 & 32.8 & $16.2(33.0)$ & 52.2 & 36.4 & $15.8(30.3)$ & 54.6 & 40.3 & $14.2(26.1)$ & 57.5 & 51.4 & $6.1(10.6)$ \\
\hline 30 & 44.5 & 28.8 & $15.7(35.3)$ & 48.4 & 32.8 & $15.6(32.3)$ & 50.3 & 36.3 & $14.0(27.8)$ & 52.6 & 46.7 & $5.9(11.4)$ \\
\hline 35 & 39.9 & 24.8 & $15.1(37.7)$ & 43.7 & 28.6 & $15.1(34.5)$ & 45.6 & 32.0 & $13.6(29.7)$ & 47.9 & 42.0 & $5.8(12.2)$ \\
\hline 40 & 35.4 & 21.1 & $14.3(40.3)$ & 39.0 & 24.6 & $14.4(36.9)$ & 40.9 & 27.9 & $13.0(31.8)$ & 43.0 & 37.4 & $5.6(13.1)$ \\
\hline 45 & 31.1 & 17.7 & $13.4(43.1)$ & 34.5 & 20.9 & $13.6(39.4)$ & 36.5 & 24.0 & $12.4(34.1)$ & 38.4 & 33.0 & $5.4(14.2)$ \\
\hline 50 & 27.1 & 14.6 & $12.5(46.1)$ & 30.2 & 17.5 & $12.7(42.1)$ & 32.0 & 20.3 & $11.7(36.5)$ & 33.8 & 28.7 & $5.1(15.3)$ \\
\hline 55 & 23.2 & 11.8 & $11.4(49.2)$ & 26.1 & 14.4 & $11.7(44.9)$ & 27.9 & 17.0 & $10.8(39.0$ & 29.4 & 24.6 & $4.9(16.5)$ \\
\hline 60 & 19.6 & 9.4 & $10.3(52.3)$ & 22.3 & 11.6 & $10.6(47.8)$ & 23.9 & 13.9 & $9.9(41.6)$ & 25.1 & 20.6 & $4.5(17.9)$ \\
\hline 65 & 16.0 & 7.2 & $8.9(55.3)$ & 18.6 & 9.2 & $9.4(50.6)$ & 20.1 & 11.2 & $8.9(44.1)$ & 21.0 & 16.9 & $4.0(19.3)$ \\
\hline 70 & 12.7 & 5.3 & $7.4(58.0)$ & 15.3 & 7.2 & 8.1 (53.1) & 16.5 & 8.9 & $7.7(46.4)$ & 16.9 & 13.5 & $3.5(20.6)$ \\
\hline$\geq 75$ & 9.7 & 3.9 & $5.9(60.1)$ & 12.6 & 5.7 & $6.9(54.8)$ & 13.3 & 6.9 & $6.4(48.1)$ & 13.1 & 10.3 & $2.8(21.7)$ \\
\hline \multicolumn{13}{|l|}{ Men } \\
\hline 20 & 43.9 & 38.2 & $5.6(12.9)$ & 46.2 & 41.0 & 5.2 (11.3) & 49.3 & 44.6 & $4.7(9.5)$ & 55.2 & 53.3 & $1.9(3.5)$ \\
\hline 25 & 39.9 & 34.4 & $5.6(14.0)$ & 42.3 & 37.1 & $5.1(12.2)$ & 45.1 & 40.6 & $4.6(10.3)$ & 50.7 & 48.8 & $1.9(3.8)$ \\
\hline 30 & 35.9 & 30.4 & $5.6(15.2)$ & 38.3 & 33.2 & $5.1(13.3)$ & 40.9 & 36.3 & 4.5 (11.2) & 46.1 & 44.2 & $1.9(4.1)$ \\
\hline 35 & 31.6 & 26.3 & $5.3(16.6)$ & 34.1 & 29.1 & $4.9(14.5)$ & 36.5 & 32.1 & $4.4(12.2)$ & 41.5 & 39.6 & $1.8(4.4)$ \\
\hline 40 & 27.5 & 22.4 & $5.0(18.2)$ & 29.7 & 24.9 & 4.7 (15.9) & 32.1 & 27.9 & $4.2(13.3)$ & 36.9 & 35.1 & $1.8(4.8)$ \\
\hline 45 & 23.4 & 18.7 & $4.7(20.1)$ & 25.5 & 21.0 & 4.4 (17.4) & 27.9 & 23.9 & $4.0(14.6)$ & 32.6 & 30.9 & $1.7(5.3)$ \\
\hline 50 & 19.9 & 15.5 & $4.4(22.2)$ & 21.6 & 17.5 & $4.1(19.2)$ & 23.9 & 20.1 & $3.8(16.0)$ & 28.1 & 26.5 & $1.6(5.8)$ \\
\hline 55 & 16.7 & 12.6 & $4.1(24.5)$ & 18.2 & 14.3 & 3.8 (21.2) & 20.2 & 16.7 & $3.6(17.7)$ & 24.0 & 22.5 & $1.5(6.4)$ \\
\hline 60 & 13.9 & 10.2 & $3.8(27.1)$ & 15.1 & 11.5 & $3.5(23.4)$ & 17.0 & 13.7 & 3.3 (19.5) & 20.1 & 18.7 & $1.4(7.0)$ \\
\hline 65 & 11.2 & 7.9 & $3.4(29.9)$ & 12.0 & 8.9 & 3.1 (25.9) & 13.8 & 10.9 & $2.9(21.4)$ & 16.5 & 15.2 & $1.3(7.7)$ \\
\hline 70 & 8.6 & 5.8 & $2.8(32.8)$ & 9.3 & 6.7 & 2.7 (28.4) & 10.8 & 8.3 & $2.5(23.4)$ & 12.9 & 11.8 & $1.0(8.5)$ \\
\hline$\geq 75$ & 6.3 & 4.1 & $2.2(35.3)$ & 7.1 & 4.9 & $2.2(30.5)$ & 8.2 & 6.1 & $2.0(25.1)$ & 9.8 & 8.9 & $0.9(9.1)$ \\
\hline
\end{tabular}

Note. The slum sector was composed of all slum census tracts, the poor sector was composed of all nonslum census tracts with mean monthly income less than or equal to US $\$ 350$, the intermediate sector was composed of all census tracts with mean monthly income greater than US $\$ 350$ and less than or equal to US $\$ 1000$, and the rich sector was composed of all census tracts with mean monthly income greater than US $\$ 1000$.

elderly, healthy life expectancy was more than twice as high in the wealthiest sector as in the slum sector, for both men and women. Moreover, when we measured healthy life expectancy against total life expectancy, we found that the wealthiest men and women had the highest proportion of healthy life after age 65 years: for men, $92.3 \%$ and for women, $80.7 \%$.

\section{DISCUSSION}

Health is defined by the WHO as a complete state of physical, mental, and social well-being. This definition transcends the absence of death and disease and incorporates quality of life.
The concept of healthy life expectancy arises from this context and is used to estimate the average time (in years) a person may expect to enjoy good health.

Since the 1980s, a growing number of studies have employed the Sullivan method ${ }^{14,18}$ because of its mathematical simplicity, the availability of required data, and the ease of interpreting results. This indicator has also been adopted for monitoring inequality in health according to socioeconomic indicators such as income, race/ ethnicity, and educational level. ${ }^{39,40}$

We aimed to estimate healthy life expectancy in Rio de Janeiro and to examine its relation to area sociodemographic conditions. Overall, our findings were consistent with previous Brazilian studies; in all strata, the percentage of lost years of healthy life increased with age, and, although women lived longer than did men, they lived relatively fewer years in good health. ${ }^{32,33}$ Regarding socioeconomic differences, our findings corroborated the findings of a study in the city of São Paulo, which showed a higher prevalence of disability in the group with lower educational attainment. ${ }^{41}$

We found pronounced inequalities between strata in life expectancy and healthy longevity, confirming previous studies that observed small-area inequalities in health conditions in Rio de Janeiro. ${ }^{29}$ Life expectancy at birth varied by as much as 13 years between residents of the wealthy and slum sectors. This difference 
may possibly be explained by extremely high homicide rates in Rio's slums, associated predominantly with conditions that generate violence, such as drug traffic. ${ }^{42}$

The increase in violent death in Rio's slums can be viewed as a reflection of the vulnerability of poor youths to the lure of criminal activity. Lack of social integration, growing hostility between the poor and the wealthy, and the inability of poor young people to find their way into the job market combine to make offers of easy money and positions of leadership offered by organized crime seductive. ${ }^{43}$ Many become involved in disputes over control of drug points of sale and in robberies and kidnappings, leading to early and violent death. A follow-up study of crack cocaine users in São Paulo showed that 5 years after treatment, 18\% had died as a result of homicide by firearms or other weapons. ${ }^{44}$

Beyond the substantial differences in life expectancy at birth, our results revealed inequalities in healthy longevity. By showing that inequality was even more striking when disability was considered, our study brings needed attention to the importance of relative poverty and the effects of social and material deprivation. As emphasized by Wilkinson and Pickett, inequality increases stress, which in turn increases risk for mental and physical disorders, such as depression and anxiety, heart disease, obesity, drug addiction, violence, and premature mortality. ${ }^{45}$

Kawachi and Kennedy ${ }^{46}$ found that the exacerbation of inequalities in distribution of wealth in several countries was accompanied by a significant residential concentration of poverty and the proliferation of urban slums. A consequence of this structural transformation is that residents of slums exhibit pronounced health inequalities in comparison with nonslum urban populations and even with poor rural populations. $^{47}$

The precarious environment of an urban slum engenders disproportionate morbidity and mortality. Residents must cope with the social consequences of living in an environment with high demographic density, surrounded by neighbors who face similar economic straits, ailments, and need for various services. ${ }^{48-50}$ By including morbidity and mortality data in our study, our analysis showed the excess burden of poor health experienced by disadvantaged populations and suggested that older people in deprived urban areas are especially susceptible to sociodemographic factors. Healthy life years among the oldest citizens should be taken into account in monitoring geographic health inequalities in large Brazilian cities. ${ }^{51}$

However, 1 limitation of our study was the estimation of the healthy status probabilities by age and gender. Because of small sample sizes in 5-year age group and gender categories, we used probabilities of healthy status predicted by logistic regression to estimate healthy life expectancies in each stratum. Although we were able to detect between-strata variation in lost years of healthy life, larger sample sizes would produce disability indicators with more precision.

Many families in Rio de Janeiro and other Brazilian cities live, for lack of better alternatives, in slum communities without basic infrastructure. The dominance of organized crime in these slums has led to ever-greater challenges to governmental action, whether aimed at improving urban infrastructure or implementing health programs. Our results show that large socioeconomic inequalities in disability exist among the elderly. Therefore, health policies focused on older people living in disadvantaged conditions should be strongly encouraged.

\section{About the Authors}

Célia Landmann Szwarcwald, Giseli Nogueira Damacena, and Tatiana Guimarães Sardinha Pereira are with the Institute of Communication and Scientific and Technologic Information in Health, Rio de Janeiro, Brazil. Jurema Corrêa da Mota is with the National School of Public Health, Oswaldo Cruz Foundation, Rio de Janeiro.

Correspondence should be sent to Célia Landmann Szwarcwald. Laboratório de Informações em Saude, Instituto de Comunicação e Informação Cientifica e Tecnologica em Saúde, Fundação Oswaldo Cruz, Av Brasil 4365, Rio de Janeiro, RJ, 21040-360,Brasil (e-mail: celials@ cict.fiocruz.br). Reprints can be ordered at http://www.ajph. org by clicking the "Reprints/Eprints" link.

This article was accepted June 7, 2010.

\section{Contributors}

C.L. Szwarcwald originated the study and wrote the article, participated in the data analysis, and coordinated the survey. J.C. Mota led the data analysis. G.N. Damacena supervised the survey and participated in writing the article. T.G.S. Pereira participated in the data analysis and literature review.

\section{Human Participant Protection}

This study was approved by the research ethics committee of the Fundação Oswaldo Cruz.

\section{References}

1. Chandola T, Ferrie J, Sacker A, Marmot M. Social inequalities in self reported health in early old age: follow-up of prospective cohort study. BMJ. 2007; 334(7601):990.

2. Cummins S, Stafford M, Macintyre S, Marmot M, Ellaway A. Neighbourhood environment and its association with self rated health: evidence from Scotland and England. J Epidemiol Community Health. 2005;59(3):

207-213.

3. Duncan GJ. Income dynamics and health. Int J Health Serv. 1996;26(3):419-444.

4. Kaplan GA. People and places: contrasting perspectives on the association between social class and health. Int J Health Serv. 1996;26(3):507-519.

5. Mackenbach JP, Kunst AE, Cavelaars AEJM, Gronhof F, Geurts JJM. Socioeconomic inequalities in morbidity and mortality in western Europe. The EU Working Group on Socioeconomic Inequalities in Health. Lancet. 1997;349(9066):1655-1659.

6. Marmot M, Ryff CD, Bumpass LL, Shipley M, Marks NF. Social inequalities in health: next questions and converging evidence. Soc Sci Med. 1997;44(6):901910.

7. Taylor-Clark KA, Mebane FE, Steelfisher GK, Blendon RJ. News of disparity: content analysis of news coverage of African American healthcare inequalities in the USA, 1994-2004. Soc Sci Med. 2007;65(3): 405-417.

8. Marmot M. The social environment and health. Clin Med. 2005;5(3):244-248.

9. Mosley WH, Cowley P. The challenge of world health Popul Bull. 1991;46(4):1-39.

10. Lubitz J, Cai L, Kramarow E, Lentzner H. Health, life expectancy, and health care spending among the elderly. N Engl J Med. 2003;349(11):1048-1055.

11. Van de Water HP, Perenboom RJ, Boshuizen HC Policy relevance of the health expectancy indicator; an inventory in European Union countries. Health Policy. 1996;36(2):117-129.

12. Verbrugge LM. Longer life but worsening health? Trends in health and mortality of middle-aged and older persons. Milbank Mem Fund Q Health Soc. 1984;62(3): 475-519.

13. Murray CJ, Lopez AD. Global mortality, disability, and the contribution of risk factors: Global Burden of Disease Study. Lancet. 1997;349(9063):14361442 .

14. Robine JM, Ritchie K. Healthy life expectancy: evaluation of global indicator of change in population health. BMJ. 1991;302(6774):457-460.

15. Manton KG, Land KC. Active life expectancy estimates for the U.S. elderly population: a multidimensional continous-mixture model of functional change applied to completed cohorts, 1982-1996. Demography. 2000;37(3):253-266.

16. Mullahy J. Live long, live well: quantifying the health of heterogeneous populations. Health Econ. 2001;10(5): 429-440.

17. Sullivan DF. A single index of mortality and morbidity. HSMHA Health Rep. 1971;86(4):347-354.

18. Mathers CD, Sadana R, Salomon JA, Murray CJ, Lopez AD. Healthy life expectancy in 191 countries, 1999. Lancet. 2001;357(9269):1685-1691. 
19. Matthews RJ, Jagger C, Hancock RM. Does socioeconomic advantage lead to a longer, healthier old age? Soc Sci Med. 2006;62(10):2489-2499.

20. Fukuda Y, Nakamura K, Takano T. Municipal health expectancy in Japan: decreased healthy longevity of older people in socioeconomically disadvantaged areas. $B M C$ Public Health. 2005;5(1):65.

21. Groenewegen PP, Westert GP, Boshuizen HC. Regional differences in healthy life expectancy in The Netherlands. Public Health. 2003;117(6):424-429.

22. Jagger C, Gillies C, Moscone F, et al. Inequalities in healthy life years in the 25 countries of the European Union in 2005: a cross-national meta-regression analysis. Lancet. 2009;372(9656):2124-2131.

23. Assis AM, Barreto ML, Santos NS, de Oliveira LP, Dos Santos SM, Pinheiro SM. Inequality, poverty, and childhood health and nutritional conditions in Northeast Brazil [in Portuguese]. Cad Saude Publica. 2007;23(10): 2337-2350.

24. Duarte EC, Schneider MC, Paes-Sousa R, da Silva JB, Castillo-Salgado C. Life expectancy at birth and mortality in Brazil, 1999: exploratory analysis of regional differences [in Portuguese]. Rev Panam Salud Publica. 2002; 12(6):436-444.

25. Caiaffa WT, Almeida MC, Oliveira CD, et al. The urban environment from the health perspective: the case of Belo Horizonte, Minas Gerais, Brazil [in Portuguese]. Cad Saude Publica. 2005;21(3):958-967.

26. Comarú Fde A, Westphal MF. Housing, urban development and health in Latin America: contrasts, inequalities and challenges. Rev Environ Health. 2004; 19(3-4):329-345

27. Guimarçães MJ, Marques NM, Melo Filho DA Szwarcwald CL. Living conditions and infant mortality: intra-urban differentials in Recife, Pernambuco State, Brazil [in Portuguese]. Cad Saude Publica. 2003;19(5): 1413-1424.

28. Monteiro RA, Schmitz B de A. Infant mortality in the Federal District, Brazil: time trend and socioeconomic inequalities [in Portuguese]. Cad Saude Publica. 2007; 23(4):767-774

29. Szwarcwald CL, Bastos FI, Barcellos C, Pina MF, Esteves MA. Health conditions and residential concentration of poverty: a study in Rio de Janeiro, Brazil. J Epidemiol Community Health. 2000;54(7):530-536.

30. Minamisava R, Nouer SS, Neto OL, Melo LK, Andrade AL. Spatial clusters of violent deaths in a newly urbanized region of Brazil: highlighting the social disparities. Int J Health Geogr. 2009;8:66.

31. Camargos MC, Rodrigues Rdo N, Machado CJ. Healthy life expectancy to Brazilian elders, 2003 [in Portuguese]. Cien Saude Colet. 2009;14(5):1903-1909.

32. Romero DE, Leite Ida C, Szwarcwald CL. Healthy life expectancy in Brazil: applying the Sullivan method. Cad Saude Publica. 2005;21(Suppl):7-18.

33. Camargos MC, Perpétuo IH, Machado CJ. Life expectancy with functional disability in elderly persons in São Paulo, Brazil [in Portuguese]. Rev Panam Salud Publica. 2005;17(5-6):379-386.

34. Mathers CD, Iburg KM, Salomon JA, et al. Global patterns of healthy life expectancy in the year 2002. BMC Public Health. 2004;4:66.

35. Szwarcwald CL, Viacava F. World health survey in Brazil, 2003 [in Portuguese]. Cad Saude Publica. 2005;21(Suppl):4-5.
36. Szwarcwald CL, Mendonca MHM, Andrade CLT. Primary health care indicators in four municipalities of the state of Rio de Janeiro, 2005: results of a domestic survey in the population [in Portuguese]. Cien Saude Colet. 2006;11(3):643-655.

37. SPSS 16.0 [computer program]. Available at: http:// www.sc.uevora.pt/spss/manual_16.php. Accessed February 22,2010 .

38. World Health Organization. International Classification of Functioning Disability and Health. Geneva, Switzerland: World Health Organization; 2001.

39. Melzer D, McWilliams B, Brayne C, Johnson T, Bond J. Socioeconomic status and the expectation of disability in old age: estimates for England. J Epidemiol Community Health. 2000;54(4):286-292.

40. Pamuk ER, Wagener DK, Molla MT. Achieving national health objectives: the impact on life expectancy and on healthy life expectancy. Am J Public Health 2004;94(3):378-383.

41. Camargos MC, Machado CJ, Rodrigues RN. Disability life expectancy for the elderly, city of Sao Paulo, Brazil 2000: gender and educational differences. J Biosoc Sci. 2007;39(3):455-463.

42. de Lima ML, Ximenes RA, Feitosa CL, et al. Violence clusters in Pernambuco, Brazil. Rev Panam Salud Publica. 2005; 18(2):122-128

43. Minayo MCS. Inequality, violence and ecology in Brazil [in Portuguese]. Cad Saude Publica. 1994;10(2): 241-250.

44. Ribeiro M, Dunn J, Sesso R, Lima MS, Laranjeira R. Crack cocaine: a five-year follow-up study of treated patients. Eur Addict Res. 2007;13(1):11-19.

45. Wilkinson R, Pickett K. The Spirit Level. Why More Equal Societies Almost Always do Better. London, UK: Allen Lane/Penguin Books; 2009.

46. Kawachi I, Kennedy BP. Health and social cohesion: why care about income inequality? BMJ. 1997;314(7086): 1037-1040

47. Rice J, Rice JS. The concentration of disadvantage and the rise of an urban penalty: urban slum prevalence and the social production of health inequalities in the developing countries. Int J Health Serv. 2009;39(4):749770 .

48. Fiscella K, Williams DR. Health disparities based on socioeconomic inequities: implications for urban health care. Acad Med. 2004;79(12):1139-1147.

49. Massey DS. The age of extremes: concentrated affluence and poverty in the twenty-first century. Demography. 1996;33(4):395-412.

50. Stafford M, Marmot M. Neighbourhood deprivation and health: does it affect us all equally? Int J Epidemiol. 2003;32(3):357-366

51. Wood R, Sutton M, Clark D, McKeon A, Bain M. Measuring inequalities in health: the case for healthy life expectancy. J Epidemiol Community Health. 2006;60(12): 1089-1092. 
Copyright of American Journal of Public Health is the property of American Public Health Association and its content may not be copied or emailed to multiple sites or posted to a listserv without the copyright holder's express written permission. However, users may print, download, or email articles for individual use. 